\title{
INVESTIGATING HEALTH RISKS FROM RIVERINE BLOOMS OF BLUE GREEN ALGAE
}

n November 1991 the world's largest recorded riverine bloom of blue green algae occurred along $1000 \mathrm{~km}$ of the Darling-Barwon river system (Figure 1). A state of emergency was declared to coordinate the provision of safe domestic water suppies for towns, Aboriginal communities and landholders.

\section{FIGURE 1}

DARLING-BARWON ALGAL BLOOMS

NOVEMBER-DECEMBER 1991, NSW

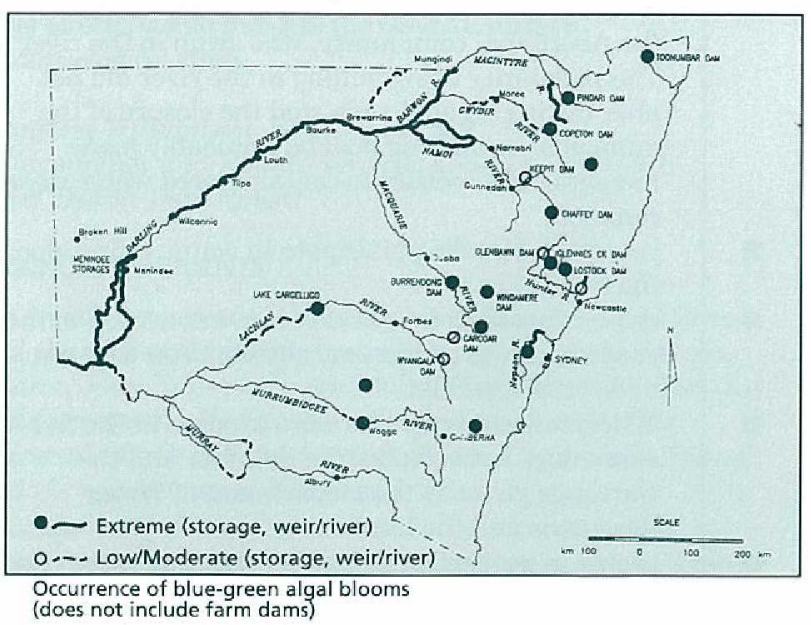

After potable water supplies had been secured for these communities, there were three outstanding public health issues:

how many individuals did not have access to an uncontaminated drinking water supply; does filtration eliminate the cyanobacterial toxins from potable water, and if not what health risks are associated with drinking filtered water; and what are the health risks of recreational exposure to water contaminated with algal blooms.

The NSW Blue Green Algae Task Force Final Report identified a number of environmental conditions which favour the development of these blooms - high nutrient levels, nitrogen:phosphate ratios less than 29 , water temperature above $20^{\circ} \mathrm{C}$, high $\mathrm{pH}$, abundant zooplankton, low water flows and reduced water turbidity. The task force concluded that:

"The Australian environment is characterised by many of these environmental conditions ... (there is) an existing and increasing potential for algal problems throughout most of western NSW and in many coastal rivers."

The likelihood of further outbreaks in the Darling-Barwon river system and elsewhere in NSW underscores the need for better information about the likely health effects of exposure to blue green algae.

In late October 1992 algal blooms had reappeared in the river between Louth and Culpaulin. The most common species found was Anabaena. This paper presents an assessment of options for future surveillance of illness related to algal blooms and the feasibility of more detailed epidemiological investigations of this problem.

\section{BACKGROUND}

Blue green algae (or cyanobacteria) are primitive photosynthetic organisms which are widely distributed in inland waterways. Two genera of these cyanobacteria dominate the records of nuisance blooms in NSW: Anabaena and Micro-cystis ${ }^{1}$. Deaths in livestock drinking contaminated water can be attributed to the neurotoxins and hepatotoxins produced by these algal species. Reports of adverse human health effects are inconsistent. Most commonly reported are eye, skin, gastrointestinal and respiratory symptoms following immersion in heavily contaminated blue green algal scum ${ }^{2}$. Concerns have been raised about the possible long-term health effects of low levels of this toxin in potable water ${ }^{3,4}$.

In collaboration with the South Australian Health Commission and the National Centre for Epidemiology and Population Health, a case definition for blue green algaerelated illness was proposed (Table 2 ).

\section{TABLE 2}

CASE DEFINITION OF BLUE GREEN ALGAL-RELATED ILLNESS

One or more of the following symptoms

- conjunctivitis without discharge

- blisters on the lips or

in the mouth

- myalgia with fever
- allergic respiratory symptoms: hayfever and asthma

- skin rash with/without itch

- gastroenteritis: nausea and/or diarrhoea and/or vomiting and/or abdominal cramps

Previous reports suggest that illness associated with blue green algae is most likely to occur within 24 hours for skin exposure and within 48 hours for consumption.

The design of meaningful epidemiological studies of illness related to this cyanobacterial bloom is severely constrained by the small populations involved and the remoteness of the affected communities. A case control study, using patients attending general practitioners in these communities as a source of both cases and control subjects, was planned. By the time this development work was completed in February 1992 the bloom had effectively receded.

\section{INVESTIGATION}

A preliminary visit was made to Wilcannia on November 2, accompanying the Royal Flying Doctor Service (RFDS) on one of its tri-weekly visits. It had the following aims:

- to conduct a pilot survey of people attending the RFDS clinic in Wilcannia which could:

- identify possible cases of cyanobacterial-related illness

— identify likely sources of exposure to contaminated water (either for drinking, bathing or swimming) 
Blue green algae

Continued from page 27

- test the feasibility of conducting a case control study based on attendances at a general practitioner or RFDS clinics;

- to obtain qualitative information from RFDS, hospital and community health staff, school principals and school nurses in Wilcannia about possible cases of cyanobacterial-related illness occurring in recent weeks in the community and about likely routes of exposure to contaminated water and high-risk groups; to determine the best methods for surveillance of disease associated with blue green algae, including refinement of the case definition; to investigate avenues for future epidemiological studies; and to enlist cooperation for any future investigations from the staff of the RFDS, Wilcannia Hospital and the local schools.

General practitioners in other communities affected by the algal bloom were contacted to request information on any recent illness that might be associated with the algal bloom and to assess their willingness to participate in a case control study.

\section{OUTCOME}

Reports from the Department of Water Resources document the rise in the number of cyanobacterial organisms in the river at Wilcannia, between October and December (Figure 2).

On October 17, two teenage girls with gastroenteritis and myalgia were seen at Wilcannia Hospital. One required admission. Symptoms had appeared after both girls had swum in the Darling River. The symptoms resolved after 48 hours. Health professionals reported no apparent increases in the incidence of illness that might be associated with blue green algae. Some residents reported itchy skin rashes after showering, even after carbon filtration of the town water supply began on October 26 .

Of the 26 patients surveyed at the Wilcannia Hospital Clinic on November 2, only one had symptoms that fitted

\section{FIGURE 2}

ANABAENA CELL COUNTS, DARLING RIVER, WILCANNIA, SEPTEMBER-NOVEMBER, 1992

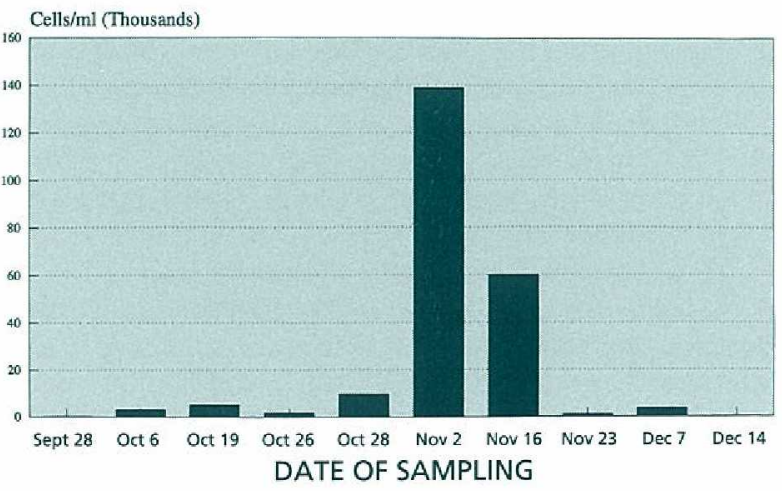

Data: River Watch Program the case definition. The symptoms reported were conjunctivitis and allergic respiratory symptoms. This person reported no contact with any source of unfiltered water affected by blue green algae.

Most participants reported drinking town water (77 per cent) and/or rain water (30 per cent). Town water was used most frequently for bathing and showering. None of the survey respondents reported a history of swimming or participation in water sports in the previous 24 hours, and only 20 per cent had other contact with unfiltered water.

School nurses and hospital staff reported that the most likely groups at risk of exposure were:

- children over six years of age, especially those from the Aboriginal community, who swim in the river. The popularity of swimming in the river did not alter during algal blooms, and the closure of the municipal swimming pool had probably made recreational exposure to contaminated water more common;

- young adults who participate in water skiing along the river;

- those exposed to untreated town water used in the garden such as gardeners, and children who run under the sprinkler;

all the townspeople who were exposed in the fiveseven days between testing the river and the warnings given by the Department of Water Resources and the local shire;

- people in properties along the river that pump water directly from the river for consumption and bathing.

Many general practitioners in these remote communities expressed a reluctance to participate in a case control study because of time limitations and their perception that it was not a significant health problem.

\section{CONCLUSION}

The results of a pilot survey in Wilcannia would suggest that despite evidence of numerous opportunities for significant recreational exposure to algal contaminated water there was very little evidence of health problems occurring as a direct result of that exposure. There were two case reports of gastrointestinal illness in river swimmers. The only other reports of illness were some of minor skin irritation.

The information provided by this investigation may not give a complete picture of illness in the community and therefore cannot provide convincing evidence that blue green algae poses no significant health problems. Therefore concerns about the safety of water contaminated with blue green algae remain.

However, we concluded that a more detailed epidemiological study, such as a case control study of patients attending general practitioners, was not warranted or feasible at this time in the isolated communities along the Darling because:

- people living in remote areas may not seek medical advice for the minor ailments which exposure to blue green algae might cause; and

回 Darling River do green algae to be a health priority. 


\section{Blue green algae}

\section{Continued from page 28}

The most promising avenue for future epidemiological research would be school-based studies. Children living along the Darling swim frequently in the river. School nurses are in a unique position to monitor even minor illness among these children. The most appropriate option for future surveillance of this potential public health problem would be to monitor continuously trends in blue green algae-related illnesses reported to school nurses in areas regularly affected by riverine blooms of blue green algae. Increases in the incidence of blue green algae-associated illnesses during or following algal blooms would indicate the need for further epidemiological study.

\section{Margaret Williamson, Stephen Corbett}

Epidemiology and Health Services Evaluation Branch NSW Health Department

\section{ACKNOWLEDGMENTS}

We greatly appreciated the help provided by Dr John Affleck and the staff of the Royal Australian Flying Doctor Service, Matron Joan Edgecombe and the staff of Wilcannia Hospital and Community Health, the principals and staff of the Wilcannia Central School and St Teresa Community School and the community at Wilcannia.

1. Blue Green Algae Final Report. Blue Green Algae Task Force, NSW Department of Water Resources, 1992

2. Hunter PR. Human Illness Associated with Freshwater Cyanobacteria (blue green algae). Public Health Laboratory Service Microbiology Digest 1991; 8:3; 96-100.

3. Falconer IR, Beresford AM, Runnegar MTC. Evidence of liver damage by toxin from a bloom of blue green algae. Med. J Aust 1983; I:511-514. 4. Collins M. Algal Toxins. Microbiological Reviews 1978; 42(4):725-746.

\section{Mammographic screening}

\section{Continued from page 26}

The satisfaction of women with the service provided at the time of the first screen will be an important influence on their decision to have future screens. A survey of women attending the screening and assessment services in the Central and Hunter Area Health Services was begun in June 1992. The results of the survey will be taken into account in the planning of the new services to ensure that service provision meets the perceived needs of women.

Printed materials about mammographic screening have been written in consultation with consumer representatives, health providers and educators and will be distributed by the services.

Community education is a major issue in developing public knowledge and acceptance of the mammographic screening program and fostering recruitment of the target population. Strategies to involve health promotion personnel in the broadest sense will be developed through a series of seminars about breast cancer and mammographic screening. The seminars will be developed on a consultative basis by the State Planning and Co-ordination Unit.

Ellen Ryan, Manager, State Planning and Co-ordination. Unit for Mammographic Screening, NSW Cancer Council.

1 Henry E. Bid to reduce breast cancer deaths. NSW Public Health Bulletin, May 1991. Volume 2, Number 5.

\section{Public HeAlth ABSTRACTS}

he following abstracts were prepared for the NSW

Public Health Network Conference in Sydney in November. The presenting author's name is underlined.

BEHAVIOURAL/RISK FACTOR SURVEY IN A RURAL AREA

Three communities in the South West Region were surveyed using a telephone-based methodology. The aims of the survey were to pilot the use of telephone surveys in a rural area and to gather local behavioural/risk factor data. The survey employed random digit dialling and the random selection of household participants, over the age of 18 years, using Kish Grids. Questions were taken (or modified) from the National Health Survey and National Heart Foundation Risk Factor Survey or were developed locally following input from a community meeting. The survey included specific questions on injuries related to farm work as well as questions on the perceived major health problems in the communities surveyed.

Students from La Trobe University Albury/Wodonga campus were trained as interviewers. Interviews were conducted between $6.30 \mathrm{pm}$ and $8.30 \mathrm{pm}$ Monday to Friday for a period of three weeks with 480 interviews being completed. Despite intense and supportive local media coverage the response rate was 62 per cent. The cost per completed interview (not including data entry and analysis and questionnaire development) was approximately $\$ 12$. Analysis of the data is being undertaken. A major issue when conducting these surveys in rural areas is the lack of experienced interviewers.

\section{Tony Kolbe, Kim Gilchrist, Elaine Clark and Neil Stubbs}

\section{THE SYDNEY AIR POLLUTION AND MORTALITY STUDY}

There has been increasing community concern over visible air pollution in Sydney and its possible effect on health. This paper reports the results of an analysis of daily death counts and environmental variables in the Sydney area of NSW for the period 1986 to 1989 . The study determines the association between daily air pollution (nitrogen dioxide, ozone and nephelometry, an indirect measure of particulates) and mortality.

All available air pollution data were obtained from the then State Pollution Control Commission from 1986 to 1989 for all sites in the Sydney area. Meteorological and mortality data were collected for the same time period and area.

Multiple linear regression models were fitted to the dataset, with non-traumatic deaths as the outcome variable. Various techniques were used to account for autocorrelation. Separate models were fitted for seasons and additional analyses were performed using the alternative outcome variables of cardiovascular deaths and cancer deaths.

The base model found significant effects of temperature, nitrogen dioxide, day of week and seasons in predicting the number of non-traumatic deaths. The reduced model accounted for 38 per cent of the variability in daily nontraumatic deaths. An increase of one log unit of nitrogen dioxide is associated with an increase in daily deaths of two. An increase in nitrogen dioxide levels from 0.0 to $2.7 \mathrm{pphm}$ would be associated with an extra two deaths on that day. If nitrogen dioxide levels increased by a further log unit, from 2.7 to $7.4 \mathrm{pphm}$, there would be a further two deaths.

Peter Lewis, John Wiodarczyk, Stephen Corbett and Tim Churches 